\title{
Using Synthetic Kerosene in Civil Jet Aircraft
}

\author{
T. A. Snijders \\ Delft University of Technology, Faculty of Aerospace Engineering \\ J.A. Melkert \\ Delft University of Technology, Faculty of Aerospace Engineering
}

Copyright @ 2008 SAE International

\begin{abstract}
TU Delft in the Netherlands is performing research into the effects of the use of synthetic kerosene in aircraft. The research program consists of both desk research and tests. In the desk research gas turbine simulations will be combined with payload range performance calculations to show engine effects and fuel consumption changes. Ground and flight tests will be performed to show safe operation on synthetic fuel and to validate the calculations. Measurements during the ground tests will show the changed emissions as a result of the synthetic fuel.
\end{abstract}

\section{INTRODUCTION}

Research into alternative aircraft fuels has seen a large increase over the last years. This concerned both short term kerosene replacement for use in current aircraft and long term replacements like hydrogen which need a complete redesign of the aircraft and fuel infrastructure. Drivers for the research into short term kerosene replacements are mainly financial and geo-political as oil prices are rising and oil is found in a relatively small number of countries. Environmental concerns have been a smaller issue. However, they are becoming increasingly important as the public demands "greener" transport.

The search for short term kerosene replacements is aimed at "drop-in" fuels that can be mixed with and used together with regular oil-based kerosene and eventually replace it. For now the most promising drop-in fuel is synthetic kerosene produced with the Fischer-Tropsch (FT) process. This fuel can be made from different feedstock, notably natural gas, coal and biomass, which are less dependent on oil price and more widely available. Because of this, synthetic kerosene is being produced, tested and used by several companies around the world, while new production plants are under development.

The physical properties of synthetic kerosene are only slightly different to those of normal kerosene whereas the chemical properties exhibit larger differences. Research at the Faculty of Aerospace Engineering of the Delft University of Technology (TU Delft) in the Netherlands is in progress to find the influence of the physical and chemical differences on the operation of existing aircraft. This research is split into a performance part, where payload-range performance is the main topic, and an environmental part where emissions and contrail formation are considered. Desk research in these areas will be combined with ground and flight tests in the TU Delft laboratory aircraft using synthetic fuel produced in the Shell Middle Distillate Synthesis plant in Malaysia.

\section{PERFORMANCE}

The performance of the aircraft when using pure synthetic kerosene or blends with normal Jet A-1 is mainly influenced by the lower density and volumetric energy density but higher gravimetric energy density of synthetic fuel when compared to Jet A-1. The lower volumetric energy density will have a reducing effect on the range of an aircraft when tank volume is limiting i.e. on maximum range of an aircraft. The higher gravimetric energy density on the other hand reduces fuel mass flow to the engines and total fuel mass needed, leading to an increased range when fuel mass or maximum take-off mass is limiting. The extent of these changes will be evaluated using gas turbine simulations and fuel consumption calculations, which in turn will be checked against ground and flight tests with the Cessna Citation II laboratory aircraft (Figure 1).

The desk research aims at looking into the effect of the use of synthetic kerosene in a range of different aircraft. They include business jet aircraft, short haul aircraft and long haul aircraft. The experimental research will be performed with the Cessna Citation laboratory aircraft which is an example of the business jet aircraft class.

GAS TURBINE SIMULATIONS - The Pratt \& Whitney Canada JT15D-4 turbofan engines on the laboratory aircraft are able to cope with a wide variety of fuels. Even Avgas, which has approximately the same gravimetric energy density as kerosene, but a $10 \%$ lower volumetric 
energy density, is allowed, albeit for a short time for lubricity and material compatibility reasons. This implies that the use of synthetic kerosene, with physical properties much closer to normal kerosene is expected to pose no problems. Still, some differences in the fuel consumption and emissions will be present. These differences will be analyzed using the gas turbine simulation program GSP which is developed by the Dutch National Aerospace Laboratory (NLR) to simulate off-design performance of gas turbines ${ }^{1}$.

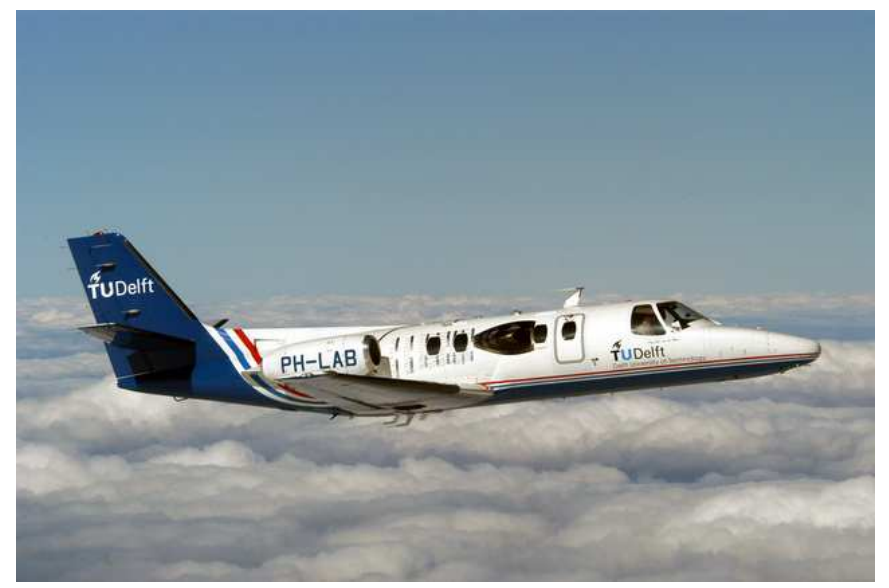

Figure 1 Cessna Citation II laboratory aircraft

Figure 2 shows the layout of the standard GSP small gas turbine model used. This model is based on the JT15D-4 engines and will be the main model for the investigation of performance and emissions for the synthetic fuel. However, models of other engines will be used when appropriate for performance calculations of other category aircraft. Control in the model is provided by a gas generator fuel control module in order to provide a sufficient fuel flow for a requested high pressure rotor speed. This enables a good comparison with ground and flight tests where rotor speed can be kept constant as well. Validation of the program and the model of the JT15D-4 engine will be done by comparing engine data from both ground and flight test with the simulation results.

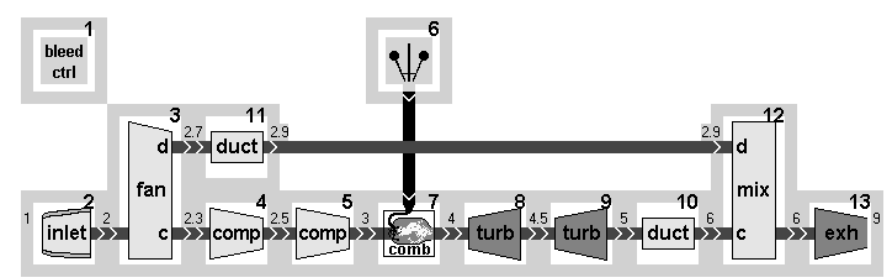

Figure 2 GSP gas turbine model

The fuel properties for Jet A-1 fuel (43.0 MJ/kg, the standard Jet A-1 fuel for GSP) are used as design fuel in the model, whereas an off-design fuel with specific energy of $44.2 \mathrm{MJ} / \mathrm{kg}$ simulates synthetic kerosene. Although a difference between the two fuels is found in the hydrogen-to-carbon ratio (H/C-ratio), 1.91 for Jet A-1 against 2.12 for FT-fuel, this is not expected to have a significant effect on engine performance.
Table 1 shows the preliminary results for the fuel flow using Jet A-1 and 100\% synthetic kerosene for take-off, climb and cruise flight. The last column shows the difference between the two fuels. As thrust remains practically constant, the difference indicates that the actual reduction in fuel consumption is less than the increase in heating value. This is a result of the offdesign parameters of the synthetic fuel.

Table 1 Preliminary GSP results

\begin{tabular}{|l|c|c|c|c|}
\hline & Unit & Jet A-1 & FT fuel & $\begin{array}{c}\text { Diff. } \\
{[\%]}\end{array}$ \\
\hline $\begin{array}{l}\text { Specific } \\
\text { energy }\end{array}$ & {$[\mathrm{MJ} / \mathrm{kg}]$} & 43.0 & 44.2 & 2.79 \\
\hline $\begin{array}{l}\text { Fuel flow } \\
\text { (Take-off } \\
\text { setting: N2 } \\
100 \%, 0 \mathrm{~m} \\
\text { ISA, M=0) }\end{array}$ & {$[\mathrm{kg} / \mathrm{s}]$} & 0.1727 & 0.1681 & -2.66 \\
\hline $\begin{array}{l}\text { Fuel flow } \\
\text { (Climb } \\
\text { setting:N2 }\end{array}$ & & & & \\
$\begin{array}{l}\text { 94.6\%, } 5 \mathrm{~km} \\
\text { ISA, M=0.31) }\end{array}$ & & & & \\
\hline $\begin{array}{l}\text { Fuel flow } \\
\text { (Cruise } \\
\text { setting: N2 } \\
83.5 \%, 10 \mathrm{~km} \\
\text { ISA, M=0.78) }\end{array}$ & & 0.0725 & 0.0707 & -2.59 \\
\hline
\end{tabular}

For fuel consumption calculations on a complete flight four parameters determine the performance: flight altitude, airspeed, rotor speed setting and fuel composition. Thrust and fuel flow will be dependent on these four variables. Creating a dataset for thrust and fuel consumption for a large number of combinations of these variables would be rather time consuming. A point for point calculation for the payload-range calculations described below would give very accurate results, but will make these calculations very lengthy.

Simulations with the gas turbine model to find the variation of the mentioned parameters and their effect on fuel consumption revealed that a linear variation with airspeed almost linear relation with altitude can be used. When considering that fuel composition is constant throughout a flight and that the rotor speed setting, which has a non-linear effect on fuel consumption, does not change continuously throughout a flight, this allows for a reduced number of simulation points.

The variation of thrust with the four variables is more complicated, as thrust does not vary linearly with the airspeed. Variation with altitude on the other hand is more or less linear up to the stratosphere while thrust does not vary at all with fuel composition as a result of the rotor speed control. Thus, the number of points to be simulated in GSP can still be lowered considerably and sufficient input is generated for the payload-range calculations. 
PAYLOAD-RANGE PERFORMANCE - The calculations to determine payload-range combinations for current aircraft are being performed using a numerical integration in Matlab combined with fuel consumption and thrust data from GSP simulations. A flight profile is assumed that incorporates all flight phases as well as a reserve fuel policy².

Maximum payload or fuel - In the case of calculating the range for maximum payload or fuel, the calculation procedure is started with the calculation of all the reserve fuel needed (see Figure 3) from the end of the flight to an alternative airport going through all flight phases in reverse order until the end of the normal cruise flight. Besides this the fuel consumption from take-off until start of the cruise is calculated, so that both cruise-start en cruise-end fuel mass are known. From these two masses the range can simply be found by applying the Breguet range equation. Total range for the specific payload is then found when the distance of en route climb, cruise and descent are added.

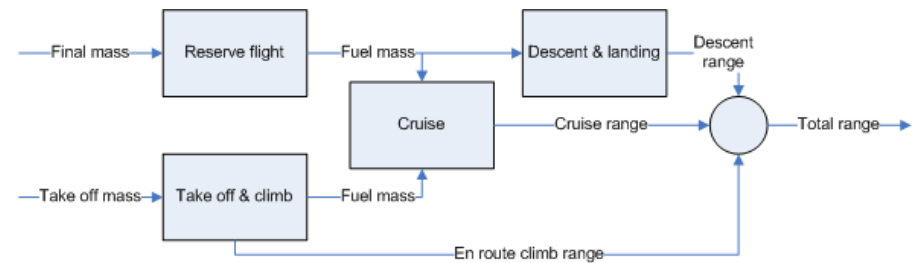

Figure 3 Calculation schedule

Typical payload-range combination - When a typical payload-range combination is used and total fuel consumption for this specific flight is requested, the calculation scheme is adapted to the new input. In this case, again the reserve fuel is determined first, but with range and cruise-end mass the mass at cruise start is found. From cruise-start mass the calculation follows the flight phases from take-off to cruise in reverse order to yield the take-off mass. Using the cruise-end mass again, the fuel used during descent and landing is found, giving the total fuel consumption for the flight.

Flight phase modules - For every different flight phase a module has been developed based on basic flight mechanics equations. A cruise flight module, used for normal and extended/reserve cruise as well as flight to an alternate airport, is based on the Breguet range equation. Other modules include take-off, climb and descent, where the first two have a constant thrust setting yielding speed and climb angle while for descent the thrust is determined from a three degree glide slope angle. Numerical integration over time yields fuel consumption for each of the flight phases as well as flight time and in the case of en route climb and descent the range.

Depending on the 'direction' of the calculation, the modules are used once or an iteration takes place. In the case of maximum payload or fuel calculations, the initial mass for all flight phases from take-off up to cruise are known, so a numerical integration over time yields the correct result directly. Furthermore, fuel mass for descent and landing for the normal flight can be determined this way. The reverse order calculation for determination of reserve fuel and as used for take-off and climb for a typical payload-range combination require iterations as only final mass is known for each phase. An estimate is therefore made for the initial mass as starting point for the integration yielding a final mass for phase. This final mass is compared to the target mass and necessary adjustments are made to the initial mass. Thus an iteration loop is formed until an initial mass is found that yields the correct final mass after numerical integration.

Some simplifications have been implemented in the connection between the flight phases. As these connections, for example the flare before touchdown, do not contribute significantly to the total fuel used and the difference between the fuels, these would complicate the calculation needlessly and are therfore omitted.

Preliminary results - It is to be expected that the maximum range for an aircraft with the maximum fuel load will be reduced due to the lower volumetric density of synthetic fuel. This reduction is not expected to be completely in line with the lower density as the total energy carried in the fuel tanks is not reduced as much. Preliminary calculation results indeed show this difference. Considering the specific point on the payloadrange diagram with maximum fuel load and a payload such that maximum take-off mass is reached, it must be noted that not only range is decreased, but the payload is increased as a result of the lower fuel mass (see Figure 4).

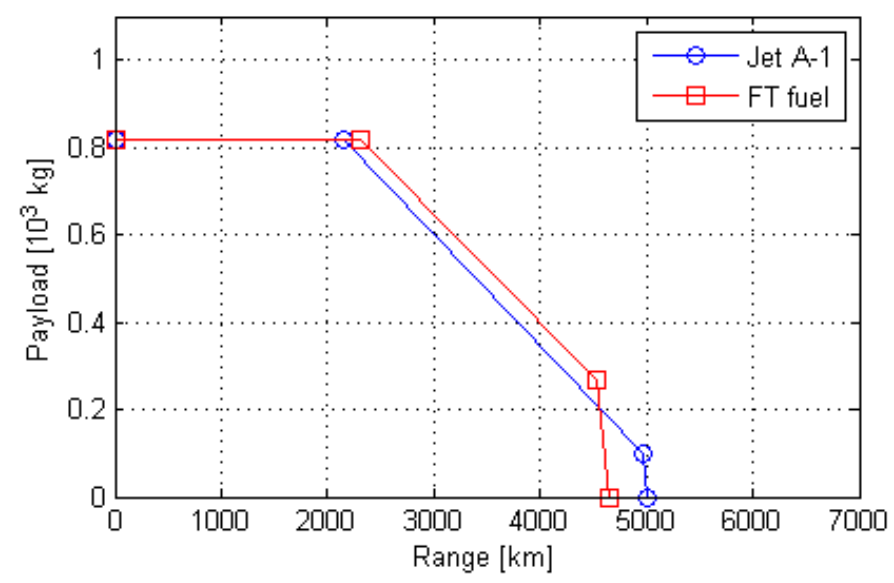

Figure 4 Example payload range diagram

When the fuel quantity is limited by the take-off mass of the aircraft, the higher gravimetric energy density means that more energy can be carried. Thus the range in this case is increased with synthetic kerosene when compared to Jet A-1. Again, this is confirmed in the preliminary results as shown in the upper right corner of the payload range diagram in Figure 4 where the range for maximum payload is increased a few percent.

Obviously, in the case of a typical payload, less fuel in terms of mass has to be carried. The reduced fuel mass means a lower aircraft mass and a decreased energy 
demand. As commercial flights generally take place inside the borders of the payload range diagram, this means that less fuel will be used when using synthetic kerosene. An initial calculation on take-off and climb performance resulting from a decreased take-off mass suggests no significant improvements in these areas.

\section{EMISSIONS}

Looking at the environmental benefits of synthetic fuel, one must note that the fuel needs to be produced at the cost of some extra energy. As this amount of energy depends on feedstock, process catalyst and other parameters, this is a complicating factor which is not easily overcome. For the time being this is not investigated. At present only the fuel as used in the aircraft is being considered.

FUEL COMPOSITION - Synthetic kerosene has a different composition that regular Jet A-1 fuel. Because of the nature of the Fischer-Tropsch process, where $\mathrm{CO}$ and $\mathrm{H}_{2}$ are combined to form synthetic oil, no pollution in the form of sulfur or nitrogen atoms is present. Furthermore, in the process mainly paraffins are formed and practically no unsaturated, aromatic or other cyclic hydrocarbons are present in the fuel. This results in the higher heating value and $\mathrm{H} / \mathrm{C}$-ratio as mentioned before.

Next to the testing of blends of Jet A-1 and synthetic fuel, giving a composition between those fuels, some additives will be needed. First of all, an anti-oxidant has to be added as indicated for synthetic fuels in standards like DEF STAN 91-91. Next, a lubricity additive and possibly a static dissipater additive will be needed as well. Finally, the laboratory aircraft's flight manual subscribes the use of an icing inhibitor. These additives can re-introduce some of the sulfur and aromatics, but the amount of additive is small when compared to the amount of fuel.

EMISSIONS - Because of the changed fuel composition, the emissions of the aircraft will change as well. When considering the reduction, in the case of a blend or sulfur-containing additive, or the complete absence of sulfur, a reduction in sulfuric oxides emission is expected. In the case of nitrogen, no substantial reduction will be expected in the emissions of nitrogen oxides. This is caused by the fact that these oxides are mainly a product of burning nitrogen in the air flowing through the engine; nitrogen from the fuel forms a very small part of this. The emission of nitrogen oxides varies with combustion temperature, which is not expected to change significantly.

The change in composition of the hydrocarbons can have several effects. The changed $\mathrm{H} / \mathrm{C}$-ratio will simply mean that less carbon dioxide and more water will be emitted. At low altitude this means a reduction in greenhouse gas emissions as water is not harmful there $^{3}$, the effects at altitude are harder to determine. The reduction or absence of aromatics and unsaturated hydrocarbons is expected to yield a lower emission of unburned hydrocarbons and black carbon particles ${ }^{4}$. Especially around airports, this reduction will greatly reduce pollution and health concerns. The amount of the reduction will be investigated during ground-runs with the aircraft.

CONTRAIL FORMATION - The formation process of contrails is still subject of investigation, but it is generally accepted that the presence of black carbon and sulfuric acid greatly accelerates the formation of contrails ${ }^{5}$. A higher sulfur content of the fuel leads to contrail formation under less humid conditions and at lower altitudes than with a low sulfur fuel. On the other hand, low sulfur fuels seem to create longer lasting contrails ${ }^{6}$. The effects of the very low to zero sulfur content of pure synthetic fuel is unknown as this lies below what was tested and reported in earlier publications.

Black carbon particles form the main part of the condensation nucleï ${ }^{7}$. As contrail formation under the absence of condensation nuclei is very unlikely ${ }^{8}$ it is expected that if a reduction in black carbon emissions is found, contrail formation will be postponed to higher humidity level and higher altitude.

The expected reduction in contrail formation at lower altitudes and lower humidity levels are expected to be (partly) offset by the increased water content in the exhaust. The extra water emitted as a result of the higher $\mathrm{H} / \mathrm{C}$-ratio increases the local humidity in the exhaust flow, which will lead to easier condensation and thus contrail formation. The net effect of the use of synthetic fuel is hard to determine theoretically and will have to be investigated using flight tests.

\section{GROUND AND FLIGHT TESTS}

The calculations and expectations for the use of synthetic fuel will have to be verified using ground and flight tests. The laboratory aircraft will be running one engine on synthetic fuel or a blend while the other engine uses regular Jet $\mathrm{A}-1$ as reference for safety reasons. Tests with each fuel combination comprise static ground tests, taxi runs and flight tests.

The ground tests will be used to both confirm safe operation of the engine on the specific fuel blend and emissions testing. Engine handling tests, with special attention to start-up and acceleration, and continuous running will be used. During the test runs engine parameters will be recorded by the onboard data acquisition system. The engine parameters that are possible to record are fuel flow, speeds of both rotors and inter turbine temperature for each engine, while total fuel used and several atmospheric variables will be measured as well. Meanwhile, a vertically traversing probe will be used to measure emission effects of the fuel and exhaust gas temperature.

Taxi and flight tests will be performed mainly to show safe operation again. This will be done by monitoring engine data throughout the flight and by performing 
engine acceleration tests and altitude relight tests. Engine and flight parameters will be recorded again and after each flight the mass and centre of gravity will be determined as an extra check on fuel consumption data. The results from both ground and flight tests will be compared with the earlier performance calculations, engine simulations and the expectations for emissions.

\section{CONCLUSION}

Fischer-Tropsch kerosene made from natural gas, coal and eventually biomass is currently the most promising alternative fuel in aviation. Desktop research, ground and flight tests are in progress at the TU Delft to find the effects on performance and emissions of the use of this fuel.

The desktop research is comprised of gas turbine simulations and payload range calculations. The gas turbine simulations will show possible changes in engine parameters and give fuel consumption values for the payload range calculations. These calculations will use basic flight mechanics equations together with gas turbine simulation results to find range or fuel needed.

Ground and flight tests will first of all be used to show safe operation of aircraft and engines on synthetic fuel. Furthermore, these tests will be used for validation of the results of the desktop research. Emission measurements will show whether the use of synthetic fuel exhibits the expected environmental benefits.

The timeframe in which the ground and flight tests will be performed depends on some technical aspects of the aircraft. Results from both practical work and desktop research will be published when the tests have been performed.

\section{REFERENCES}

1. Visser, W.P.J. and M.J. Broomhead, "GSP A generic object-oriented gas turbine simulation environment", NLR-TP-2000-267, National Aerospace Laboratory NLR, Amsterdam, The Netherlands, 2000
2. Torenbeek, E., Synthesis of Subsonic Airplane Design, Delft University Press, Delft, The Netherlands, 1982

3. Penner, J.E. et al, "Aviation and the Global Atmosphere", Cambridge University Press, Cambridge, United Kingdom, 1999

4. Edwards, T. et al, "Fischer-Tropsch Jet Fuels Characterization for Advanced Aerospace Applications", AIAA-2004-3885, American Institute of Aeronautics and Astronautics, Reston, Virginia, USA, 2004

5. Gierens, K. and U. Schumann, "Colors of contrails from fuels with different sulfur contents", Journal of Geophysical Research, vol. 101 pages 16,73116,736, American Geophysical Union, Washington D.C., USA, 1996

6. Schumann, U. et al, "In situ observation of particles in jet aircraft exhaust and contrails for different sulfur-containing fuels", Journal of Geophysical Research, vol. 101 pages 6853-6,869, American Geophysical Union, Washington D.C., USA, 1996

7. Wyslouzil, B.E. et al, "Observation of hydration of single, modified carbon aerosols", Geophysical Research Letters, vol. 21 pages 2107-2110, American Geophysical Union, Washington D.C., USA, 1994

8. Kärcher, B. et al, "Contrail Formation: Homogeneous nucleation of $\mathrm{H}_{2} \mathrm{SO}_{4} / \mathrm{H}_{2} \mathrm{O}$ droplets", Geophysical Research Letters, vol. 22 pages 1501-1504, American Geophysical Union, Washington D.C., USA 1998

\section{CONTACT}

\section{T.A. Snijders}

Delft University of Technology

Faculty of Aerospace Engineering

Aerospace for Sustainable Engineering and Technology

Kluyverweg 1

2629 HS Delft

The Netherlands

T.A.Snijders@TUDelft.nl 